Check for updates

Cite this: RSC Adv., 2019, 9, 15115

Received 8th March 2019

Accepted 9th May 2019

DOI: $10.1039 / c 9 r a 01781 j$

rsc.li/rsc-advances

\section{Electrocarboxylation of 1-chloro-(4- isobutylphenyl)ethane with a silver cathode in ionic liquids: an environmentally benign and efficient way to synthesize Ibuprofen $\uparrow$}

\begin{abstract}
Silvia Mena, (iD) Jessica Sanchez and Gonzalo Guirado (D) *
Electrocarboxylation of organic halides is one of the most widely used approaches for valorising $\mathrm{CO}_{2}$. In this manuscript, we report a new greener synthetic route for synthesising 2-(4-isobutylphenyl)propanoic acid, Ibuprofen, one of the most popular non-steroidal anti-inflammatory drugs (NSAIDs). The joint use of electrochemical techniques and ionic liquids (ILs) allows $\mathrm{CO}_{2}$ to be used as a $\mathrm{C}_{1}$-organic building block for synthesising Ibuprofen in high yields, with conversion ratios close to $100 \%$, and under mild conditions. Furthermore, the determination of the reduction peak potential values of 1-chloro-(4isobutylphenyl)ethane in several electrolytes (DMF, and ionic liquids) and with different cathodes (carbon and silver) makes it possible to evaluate the most "energetically" favourable conditions for performing the electrocarboxylation reaction. Hence, the use of ILs not only makes the electrolytic media greener, but they also act as catalysts enabling the electrochemical reduction of 1-chloro-(4-isobutylphenyl)ethane to be decreased by up to $1.0 \mathrm{~V}$.
\end{abstract}

\section{Introduction}

Carbon dioxide $\left(\mathrm{CO}_{2}\right)$ is known as a greenhouse gas and is the most important contributor to global warming. The chemical properties of $\mathrm{CO}_{2}$ make it an interesting candidate for developing new green sustainable chemistry, since it is abundant, non-toxic, non-flammable, and a low cost material. Moreover, its $\mathrm{C}_{1}$ carbon skeleton is interesting for making longer molecules. Therefore, one of the main challenges for the scientific community is to eliminate or re-use $\mathrm{CO}_{2}$ in order to obtain other types of compounds with high added value, such as carboxylic derivatives. In this sense, different methodologies are currently being developed to minimise its production, such as the carbon capture and storage (CCS) and carbon capture and utilisation (CCU) technologies. ${ }^{\mathbf{1}-\mathbf{6}}$

According to the literature, ${ }^{7-9}$ different organic synthetic routes have been developed using $\mathrm{CO}_{2}$ as a reactant. Direct carboxylation of carbon nucleophile using $\mathrm{CO}_{2}$ as an electrophile is a straightforward route to prepare carboxylic acids. On the other hand, $\mathrm{CO}_{2}$ is highly reactive with carbon nucleophiles, such as Grignard and organolithium reagents. The main disadvantage of those processes is the use of toxic reagents that generate a large amount of waste. An attractive alternative is the

Departament de Quimica, Universitat Autònoma de Barcelona, 08193-Bellaterra, Barcelona, Spain. E-mail: gonzalo.guirado@uab.cat

$\dagger$ Electronic supplementary information (ESI) available. See DOI: $10.1039 / \mathrm{c} 9 \mathrm{ra} 01781 \mathrm{j}$ use of organic electrochemical techniques for obtaining high valuable carboxylation products, since they can improve environmental conditions. In this sense, electrochemical techniques may offer the possibility to activate the $\mathrm{CO}_{2}$ through a electrocarboxylation process..$^{10-19}$ Electrocarboxylation of organic halides is one of the most widely used approaches for valorising $\mathrm{CO}_{2}$. In a first step, a one electron transfer process generates the organic radical, which later converts to an anion though a second reduction electron transfer, and a halide anion (Scheme 1). ${ }^{20}$ The key step of this approach relies on the reduction potential value of the organic halides and on the stability of the organic anion formed after the reduction process. Furthermore, in the recent years, many studies have appeared in which a silver electrode is a good option to reduce the reduction potential in the carbon-halide cleavage reaction. ${ }^{21-29}$

The electrochemical approach for synthesis of non-steroidal anti-inflammatory drugs (NSAIDs) (e.g. Naproxen ${ }^{\mathbf{3 0}}$ and Ibuprofen $^{30-32}$ ) has been previously performed, obtaining from moderate to good yields. However, the main drawbacks associated with those electrocarboxylation processes were the use of organic solvents, which are well-known to be hazardous and flammable, ${ }^{14}$ the use of large quantities of supporting electrolyte, ${ }^{\mathbf{1 6}}$ and either the use of toxic redox mediators, or high reduction potential values. In this sense, in the current manuscript we propose an attractive alternative to these electrocarboxylation processes by: (1) the replacement of conventional electrochemical solvents with Ionic Liquids (ILs). ILs have been 


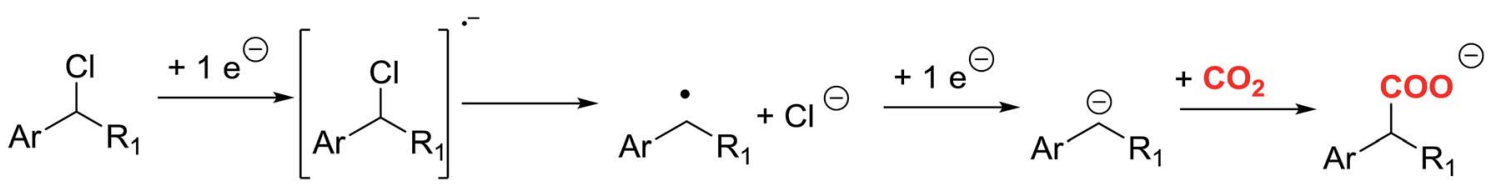

Scheme 1 Electrochemical carboxylation mechanism of benzyl halides.

widely used as environmentally friendly solvents, electrolytes, as well as catalysts, ${ }^{33-41}$ and (2) the use of a silver cathode for decreasing the reduction potential values required for the cleavage of the halide-carbon bond, avoiding the use of either toxic mediators. Hence, this manuscript reports a new, more environmentally friendly, approach for synthesising 2-(4-(2methylpropyl)phenyl)propanoic acid (Ibuprofen) by using green technologies (electrochemistry), green solvents (RTILs), and $\mathrm{CO}_{2}$ feedstock.

\section{Experimental section}

\subsection{Materials}

Carbon dioxide, $\mathrm{CO}_{2}$, and nitrogen, $\mathrm{N}_{2}$, were obtained from Carburos Metálicos S.A. (a purity of 99.9999\%). 1-Chloro-(4isobutylphenyl)ethane (1) was synthesised following that in the literature. ${ }^{42} \quad N$-Methyl- $N$-propylpiperidinium bis(trifluoromethanesulfonyl)imide (PP13 TFSI, purity 99.5\%, $\mathrm{H}_{2} \mathrm{O} \leq$ 0.05\%), 1-methyl-1-ethylimidazolium bis(trifluoromethanesulfonyl)imide (EMIM TFSI, purity 99\%, $\mathrm{H}_{2} \mathrm{O} \leq$ $0.2 \%$ ) were acquired from Solvionic, and were dried under vacuum using activated molecular sieves for $24 \mathrm{~h}$ to make sure that the amount of water was always less than $\mathrm{H}_{2} \mathrm{O} \leq 0.001 \%$ (Scheme 2).

\subsection{Cyclic voltammetry experiments}

An electrochemical conical cell is used for the set-up of the three-electrode system. For CV experiments, the working electrode is a vitreous carbon disk of $1 \mathrm{~mm}$ diameter. It is polished using a $1 \mathrm{~mm}$ diamond paste. The counter electrode is a Pt disk of $<1 \mathrm{~mm}$ diameter. All the potentials are reported versus an aqueous saturated calomel electrode (SCE) isolated from the working electrode compartment by a salt bridge. The salt solution of the reference calomel electrode is separated from the electrochemical solution by a salt-bridge ended with a frit, which is made of a ceramic material, allowing ionic conduction between the two solutions and avoiding appreciable contamination. Ideally, the electrolyte solution present in the bridge is the same as the one used for the electrochemical solution, in order to minimise junction potentials. The error associated with the potential values is less than $5 \mathrm{mV}$. The ohmic drop can be one of the main sources of error when ILs are used as solvents, since they are more resistive media than aprotic polar solvents with $0.1 \mathrm{M}$ concentration of supporting electrolyte.

The number of electrons involved in the first reduction process of $\mathbf{1}$ was determined by comparison with very wellknown one-electron reduction of fluorenone and nitrobenzene (redox probes), in the same medium using the same electrochemical set-up, by terms of cyclic voltammetry. The number of electrons involved in this first electron transfer was also confirmed by controlled-potential electrolysis. ${ }^{43-46}$

\subsection{General procedure for the electrocarboxylation processes}

Compound 1 was electrolysed at a negative potential of $0.1 \mathrm{~V}$ more negative than the $E_{\mathrm{pc}}$ potential value under nitrogen or carbon dioxide saturated solutions. When the reaction is completed, the resulting solution in the electrolysis is extracted into water/ether mixtures. The organic layer is dried with $\mathrm{Na}_{2} \mathrm{SO}_{4}$ and evaporated to yield a residue that is analysed by gas chromatography-mass spectrometry, and Proton Nuclear Magnetic Resonance $\left({ }^{1} \mathrm{H}-\mathrm{RMN}\right)$. When pure ILs are used as<smiles>CC(C)Cc1ccc(C(C)Cl)cc1</smiles>

1<smiles>COc1ccc(CC(C)C)cc1</smiles>

$1^{-}$<smiles></smiles><smiles>O=S(=O)(NS(=O)(=O)C(F)(F)F)C(F)(F)F</smiles>

PP13 TFSI<smiles>CCc1ccc(CC(C)C)cc1</smiles>

2<smiles>CC(=O)C(C)c1ccc(CC(C)C)cc1</smiles>

3

4<smiles></smiles>

EMIM TFSI

Scheme 2 Diagram of the structures. 
electrolyte, the products of the electrolysed solution are extracted with ether, allowing to recover almost an $80 \%$ of the IL at the end of the experiment. This organic layer was lately washed with water and dried with $\mathrm{Na}_{2} \mathrm{SO}_{4}$ (Scheme 3). Besides, the IL recovered was dried and reused in a new electrochemical process without loss of Ibuprofen yield.

All products obtained, and the commercial analogues (1chloro-(4-isobutylphenyl)ethane, 1-ethyl-4-isobutylbenzene, 2(4-(2-methylpropyl)phenyl)propanoic acid) were characterised by ${ }^{1} \mathrm{H}$-NMR. Measurements were made using a Bruker DPX360 (360 MHz) (Billerica, MA, USA) spectrometer. Proton chemical shifts were reported in ppm $(\delta)\left(\mathrm{CDCl}_{3}, \delta=7.26\right.$, or $\mathrm{CD}_{3} \mathrm{CN}, \delta=$ 1.94). The $J$ values are reported in $\mathrm{Hz}$.

\subsection{Determination of the $\mathrm{CO}_{2}$ concentration in ILs}

A thermal mass flowmeter of modular construction with a 'laboratory style' pc-board housing (EL-FLOW® Mass Flow Meter/Controller) from Bronkhorst $\mathrm{Hi}-\mathrm{Tec}$, was used to monitor the $\mathrm{CO}_{2}$ concentrations in the solution. ${ }^{47}$ Control valves were integrated to measure and control a gas flow from the lowest range of 0.2 up to $10 \mathrm{ml} \mathrm{min}{ }^{-1}$.

\section{Results and discussion}

3.1. Electrochemical reduction of 1-chloro-(4isobutylphenyl)ethane (1) under inert atmosphere

Cyclic voltammetry of compound $\mathbf{1}$ was recorded in different solvents (DMF + 0.1 $\mathrm{M} \mathrm{TBABF}_{4}$, EMIM TFSI, PP13 TFSI, and a DMF-PP13 TFSI (50:50)), and scan rates using glassy carbon electrode as a cathode under a $\mathrm{N}_{2}$ atmosphere. In all cases, compound 1 shows a two-electron irreversible reduction peak (Fig. 1), as was expected for these types of compounds. The number of electrons involve in the first reduction process is determined by comparison with the fluorenone, our standard, in the same medium and with the same electrochemical set-up. Hence, in a first cathodic scan, a two electron irreversible reduction wave appears between -1.9 and $-2.4 \mathrm{~V} v s$. SCE, depending on the solvent. The peak width value $\left(\Delta E_{\mathrm{p}}\right)$ is always more than $150 \mathrm{mV}$ (at $0.3 \mathrm{~V} \mathrm{~s}^{-1}$, Table 1), which means that compound 1 shows a slow electron transfer (charge transfer coefficient $(\alpha) c a .0 .3) .^{48}$ The analysis of the peak current values (and their dependence with the concentration and the scan rate), the peak potential values (and their dependence with the concentration) indicates that the chemical reaction coupled to the electron transfer is a first order reaction. In the corresponding anodic counter scan an oxidation peak at $c a .1 .1 \mathrm{~V}$ is

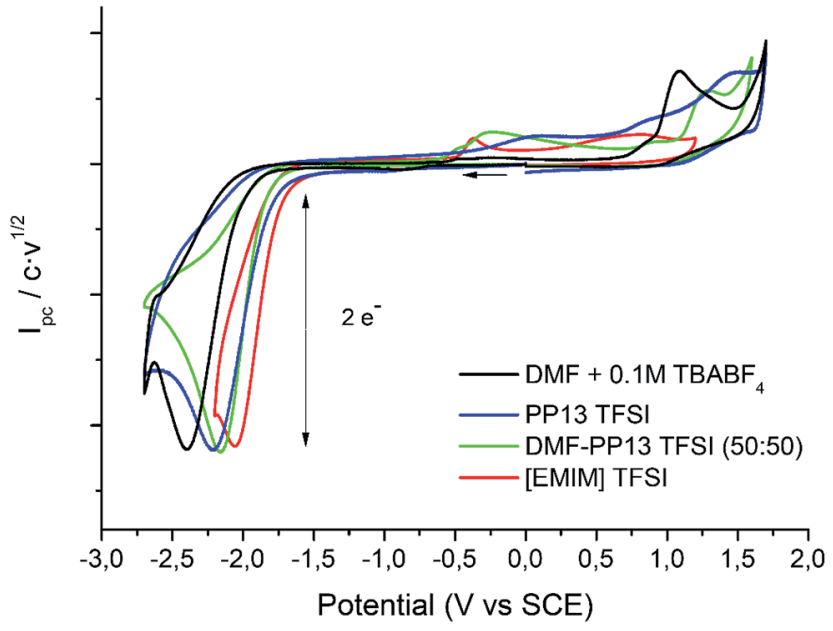

Fig. 1 Cyclic voltammograms (scan rate $0.5 \mathrm{~V} \mathrm{~s}^{-1}$ ) at $25^{\circ} \mathrm{C}$ on $\mathrm{GC}$ electrode of a solution of $10 \mathrm{mM}$ of 1 in DMF $+0.1 \mathrm{M} \mathrm{TBABF}_{4}$ (black line), PP13TFSI (blue line), DMF-PP13 TFSI (50:50) and EMIM TFSI (red line).

detected, which is attributed to the oxidation of chloride anion. ${ }^{49}$ A closer look at the CVs also reveals that when EMIM TFSI is used as a solvent, a new peak appears $-0.3 \mathrm{~V} v$ s. SCE. This new peak is oxidation related to imidazolium moieties formed after the electrochemical reduction of EMIM. This IM radical is immediately reduced at the electrode surface to its anion, and on the $\mathrm{CV}$ return its oxidation is observed at $c a .0 .1 \mathrm{~V}$ vs. SCE. ${ }^{50-54}$ The cyclic voltammograms performed in PP13 TFSI and DMF-PP13 TFSI also show an irreversible oxidation peak at $-0.28 \mathrm{~V}$ in the corresponding anodic counter scan. The appearance of this peak indicates that a new electroactive species is present in the solution. Hence, the oxidation peak should be associated with the oxidation of the benzylic anion intermediate $\mathbf{1}^{-}$(Schemes 4 and 5, Fig. 2). The irreversible wave at $E_{\mathrm{pa}}=-0.28 \mathrm{~V} v s$. SCE disappears upon the addition of water and acid, which agrees with the presence of the anionic intermediate.

Taking the value $E_{\mathrm{pc}}$ value obtained for the electrochemical reduction of 1 in $\mathrm{DMF}+0.1 \mathrm{M} \mathrm{TBABF}_{4}$ as a reference value (Table 1 ), the $E_{\mathrm{pc}}$ values obtained in all the ILs are positively shifted, which means that the cation of the IL acts as a catalyst (as was previously pointed out by us and some other authors). ${ }^{35}$ The reduction potential can be lowered to more than $0.30 \mathrm{~V}$ (7 kcal mol ${ }^{-1}$ ) with respect to DMF $+0.1 \mathrm{M} \mathrm{TBABF}_{4}$ (Table 1, entries 1-4). This fact can be explained by taking in to account that the IL is a pure ion solvent, whereas the concentration of

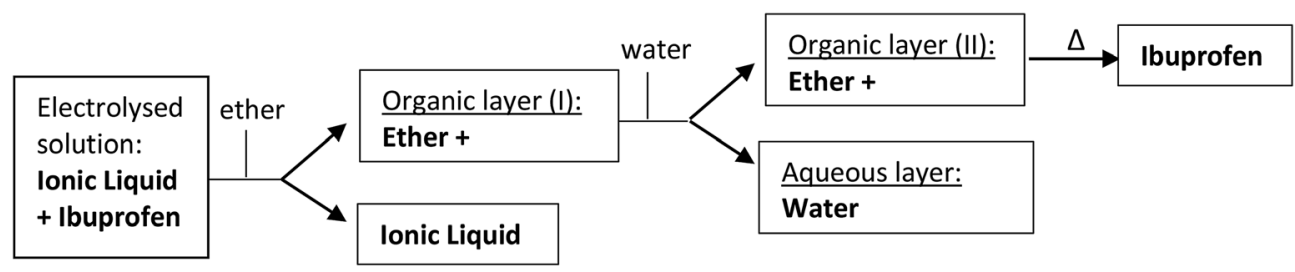

Scheme 3 Schematic process for Ibuprofen purification and IL recovery after the electrocarboxylation reaction. 
Table 1 Cathodic peak potential $\left(E_{\mathrm{pc}}\right.$ in $\mathrm{V}$ ), $\Delta E_{\mathrm{p}}=\left|E_{\mathrm{pc}}-E_{\mathrm{pc} / 2}\right|$ (in $\mathrm{mV}$ ), scan rate: $0.3 \mathrm{~V} \mathrm{~s}^{-1}$, concentration ca. $5 \mathrm{mM}$, Charge transfer coefficient $(\alpha)$ for 1 in several solvents using glassy carbon as a working electrode at $25^{\circ} \mathrm{C}$ under nitrogen atmosphere

\begin{tabular}{|c|c|c|c|c|c|}
\hline Entry & Solvent & $E_{\mathrm{pc}}(\mathrm{V})$ & $\Delta E_{\mathrm{p}}^{b}(\mathrm{mV})$ & $\alpha$ & Number of electrons \\
\hline 1 & $\mathrm{DMF}^{a}$ & -2.42 & 180 & $0.26_{1}$ & $1.9_{5}$ \\
\hline 2 & EMIM TFSI & -2.03 & 156 & $0.31_{3}$ & $2.1_{2}$ \\
\hline 4 & PP13 TFSI & -2.15 & 212 & $0.22_{2}$ & $1.8_{5}$ \\
\hline
\end{tabular}

${ }^{a}$ The DMF solution contains $0.1 \mathrm{M}$ of $N$-tetrabutylammonium tetrafluoroborate $\left(\mathrm{TBABF}_{4}\right) \cdot{ }^{b} \Delta E_{\mathrm{p}}(\mathrm{mV})$ is the peak width value $E_{\mathrm{pc}}-E_{\mathrm{pc} / 2}$ at $0.3 \mathrm{~V} \mathrm{~s}{ }^{-1}$.

the counter-cation is considerably lower the DMF solution, where "only" a $0.1 \mathrm{M}$ concentration of tetrabutylammonium cation is present.

In order to determine the nature of the product formed after the first electron transfer of $\mathbf{1}$, a control potential electrolysis at $-2.2 \mathrm{~V}$ vs. SCE under inert atmosphere was performed in the above-mentioned electrolytic media (a control potential electrolysis at $-2.5 \mathrm{~V} v s$. SCE was performed in DMF). 1-Ethyl-4-isobutylbenzene, 2, was obtained as a unique quantitative product (100\%) in DMF, DMF/PP13, and PP13 after the passage of $2 \mathrm{~F}$. Overall, the electrochemical reduction mechanism of $\mathbf{1}$ is a two electron ECE mechanism (Scheme 4). In a first reduction step, a radical anion is formed (electrochemical reaction, E), which undergoes $\mathrm{C}-\mathrm{Cl}$ cleavage, leading to the corresponding organic radical and halide anion (elementary reaction step, $\mathrm{C}$ ). The radical is reduced at this potential value, leading to the corresponding anion (electrochemical reaction, E). In a last protonation step the organic anion evolves to 2 .

When EMIM TFSI is used as solvent the reactant was recovered at the end of the process, and only decomposition products related to the reduction of EMIM cation were observed. These results can be easily rationalised taking into account that EMIM cation is reduced at $-2.3 \mathrm{~V}$, so the solvent is partially reduced at this potential. Thus, EMIM TFSI was discarded for the upcoming electrocarboxylation processes.
Eq. 1<smiles>CC(C)Cc1ccc(C([18OH])Cl)cc1</smiles>

1

Eq. 2<smiles>CC(C)Cc1ccc(C(C)C)cc1</smiles>

Eq. 3<smiles>CCc1ccc(CC(C)C)cc1</smiles>
$+1 \mathrm{e}^{-}$

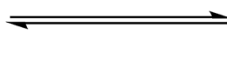<smiles>CC(C)Cc1ccc(C(Cl)C(C)C)cc1</smiles><smiles>CC(C)Cc1ccc(CCCl)cc1</smiles>

C<smiles>CCc1ccc(CC(C)C)cc1</smiles><smiles>CC(C)Cc1ccc(C(C)C)cc1</smiles>

Scheme 4 Electrochemical reduction mechanism of 1. 


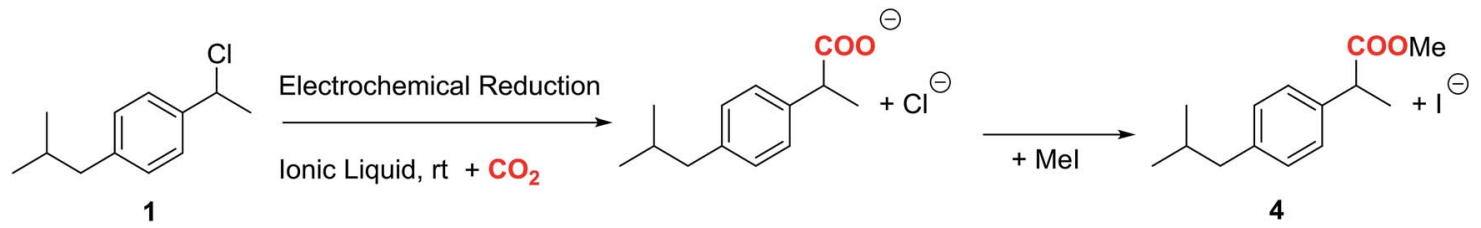

Scheme 5 Electrocarboxylation of 1 under $\mathrm{CO}_{2}$ atmosphere adding Mel as methylated agent at the end of the controlled-potential electrolysis.

\subsection{Electrochemical reduction of 1-chloro-(4- isobutylphenyl)ethane (1) under $\mathrm{CO}_{2}$ atmosphere with carbon vitreous working electrode}

Fig. 2 shows the cyclic voltammograms of $\mathbf{1}$ in one of the electrolytic media employed under $\mathrm{CO}_{2}$ atmosphere. In all the cases, a two electron reduction wave was observed at $c a .-2.20 \mathrm{~V}$ vs. SCE in the initial cathodic scan, whereas an oxidation peak at $c a .1 .1 \mathrm{~V}$ vs. SCE, which corresponds to the oxidation of chloride ion, is also detected in the ensuing anodic scan.

Taking advantage of the long lifetime of $\mathbf{1}^{-}$in ionic liquid based electrolytes, several electrocarboxylation processes where attempted. The selected electrolyte was previously pre-saturated with $\mathrm{CO}_{2}$ to minimise undesired protonation side reactions. Hence controlled-potential electrolysis of $\mathbf{1}$ was performed using a graphite bar electrode under a saturated $\mathrm{CO}_{2}$ atmosphere in DMF and ILs. The reduction processes were easily monitored by means of cyclic voltammetry (Fig. 3). In all the cases Ibuprofen was obtained in moderate to good yields (Table 2). The used of PP13 TFSI IL as a co-solvent, not only makes the reaction greener, but also increases the yield up to $75 \%$. This result can be explained due to a higher hydrophobicity of the media, since these electrocarboxylation reactions are very sensitive to the presence of water. Finally, when pure IL electrolyte is used, the product yield increases up to $c a$. $90 \%$ over consumed reactant, with the $E$-factor being close to 1 (Table 2, entries 5 and 10). Hence, no other products apart from the Ibuprofen and the starting material were recovered. Moreover,

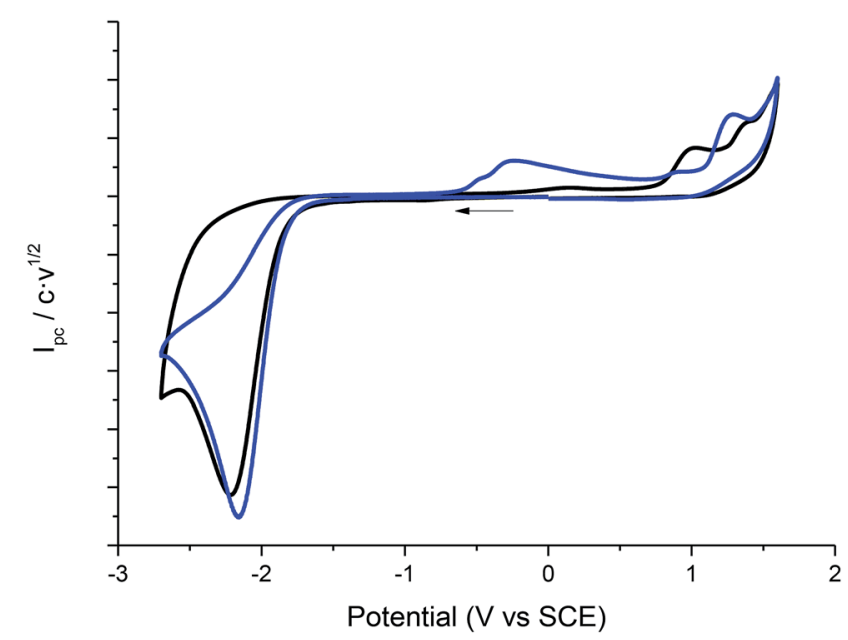

Fig. 2 Cyclic voltammograms (scan rate $0.5 \mathrm{~V} \mathrm{~s}^{-1}$ ) at $25^{\circ} \mathrm{C}$ on a GC electrode of $10 \mathrm{mM}$ of 1 at $\mathrm{CO}_{2}$ atmosphere (blue line), inert atmosphere (black line) in PP13 TFSI-DMF (1: 1). a methylated agent, such as iodomethane, was added it is possible to obtain methylated Ibuprofen, 4 (Scheme 5). Finally, note, that for obtaining yields close to $100 \%$, the IL should be previously dried, the use of commercial IL $(\leq 0.05 \%$ water content) also leads also to $20 \%$ of protonated compound 2 .

\subsection{Electrochemical reduction of 1-chloro-(4- isobutylphenyl)ethane (1) under $\mathrm{CO}_{2}$ atmosphere with silver working electrode}

It is well-known that the use of silver cathodes reduces the reduction potential value where the carbon-halide cleavage reaction takes place. ${ }^{21-29}$ Due to the electrocatalytic effect of silver, it was decided to use a silver electrode as a cathode for the electrocarboxylation process in ILs.

Cyclic voltammetry of compound $\mathbf{1}$ was recorded, using a silver electrode as a cathode under $\mathrm{N}_{2}$ atmosphere, in EMIM TFSI (to try to improve the results obtained with the carbon electrode) and PP13 TFSI (Fig. 4). In all cases, compound 1 shows the same general behaviour as in the case of using a glassy carbon electrode. Hence, in a first cathodic scan, a two electron irreversible reduction wave appears between -1.7 and $-2.0 \mathrm{~V} v s$. SCE depending on the ionic liquid. Taking the $E_{\mathrm{pc}}$ value obtained for the electrochemical reduction of $\mathbf{1}$ in the ionic liquids with glassy carbon electrode as a reference value (Table 1), the $E_{\mathrm{pc}}$ values obtained using silver electrode are considerably positively shifted. The reduction potential can be lowered to more than $0.07 \mathrm{~V}\left(1.61 \mathrm{kcal} \mathrm{mol}^{-1}\right)$ and $0.49 \mathrm{~V}$

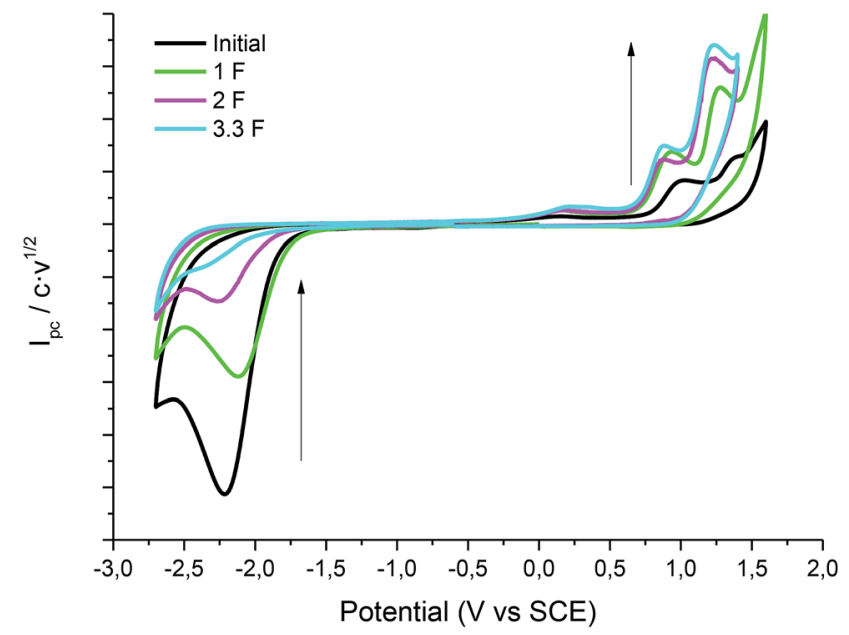

Fig. 3 Cyclic voltammograms (scan rate $0.5 \mathrm{~V} \mathrm{~s}^{-1}$ ) at $25^{\circ} \mathrm{C}$ on a GC electrode showing controls of the control potential electrolysis of 1 at $\mathrm{CO}_{2}$ atmosphere in DMF-PP13 TFSI (1:1). 
Table 2 Results of electrocarboxylation of 1 to obtain $\mathrm{R}-\mathrm{COOH} / \mathrm{Me}$

\begin{tabular}{|c|c|c|c|c|c|c|c|}
\hline \multirow[b]{2}{*}{ Entry } & \multirow[b]{2}{*}{ Solvent } & \multirow[b]{2}{*}{$E_{\text {applied }}$} & \multirow[b]{2}{*}{$\mathrm{C} \mathrm{mol}^{-1}$} & \multicolumn{2}{|c|}{$\mathrm{R}-\mathrm{COOH}$ (Ibuprofen isolated yield) } & \multirow{2}{*}{$\begin{array}{l}\text { Reagent recovery } \\
(\%)\end{array}$} & \multirow{2}{*}{$\begin{array}{l}\mathrm{R}-\mathrm{H} \\
(\%)\end{array}$} \\
\hline & & & & Yield $^{a}(\%)$ & Conversion rate $^{b}(\%)$ & & \\
\hline 1 & $\mathrm{DMF}^{c}$ & -2.6 & 3.0 & 61 & 82 & 26 & 13 \\
\hline 2 & EMIM TFSI & -2.2 & 3.0 & - & - & - & - \\
\hline 3 & DMF-IL $^{d}(50-50 \%)$ & -2.4 & 3.3 & 75 & 83 & 10 & 15 \\
\hline 4 & PP13 TFSI $^{e}$ & -2.4 & 1.7 & 25 & 57 & 56 & 19 \\
\hline \multirow[t]{3}{*}{5} & PP13 TFSI ${ }^{f}$ & -2.4 & 1.7 & 47 & 94 & 50 & 3 \\
\hline & & & & \multicolumn{2}{|c|}{$\begin{array}{l}\mathrm{R}-\mathrm{COOMe} \text { (methylated Ibuprofen } \\
\text { isolated yield) }\end{array}$} & \multirow{2}{*}{$\begin{array}{l}\text { Reagent recovery } \\
(\%)\end{array}$} & \multirow{2}{*}{$\begin{array}{l}\mathrm{R}-\mathrm{H} \\
(\%)\end{array}$} \\
\hline & Solvent & $E_{\text {applied }}$ & $\mathrm{C} \mathrm{mol}{ }^{-1}$ & Yield (\%) & Conversion rate & & \\
\hline 6 & $\mathrm{DMF}^{c}$ & -2.6 & 3.0 & 61 & 87 & 30 & 9 \\
\hline 7 & EMIM TFSI & -2.2 & 3.0 & - & - & - & - \\
\hline 8 & DMF-IL ${ }^{d}(50-50 \%)$ & -2.4 & 3.0 & 86 & 86 & - & 14 \\
\hline 9 & $\mathrm{PP} 13 \mathrm{TFSI}^{e}$ & -2.4 & 1.7 & 26 & 67 & 61 & 13 \\
\hline 10 & PP13 TFSI ${ }^{f}$ & -2.4 & 1.7 & 48 & 96 & 50 & 2 \\
\hline
\end{tabular}

${ }^{a}$ Percent yield over isolated product. ${ }^{b}$ Percent of Ibuprofen over consumed reactant. ${ }^{c}$ The DMF solution contains $0.1 \mathrm{M}$ of $N$-tetrabutylammonium tetrafluoroborate $\left(\mathrm{TBABF}_{4}\right)$ dried under vacuum and molecular sieves (less than $0.01 \%$ of water). ${ }^{d}$ Mixture $1: 1$ of $\mathrm{DMF}+0.1 \mathrm{M} \mathrm{TBABF}{ }_{4}$ and $\mathrm{PP} 13$ TFSI dried under vacuum and molecular sieves (less than $0.01 \%$ of water). ${ }^{e}$ PP13 TFSI commercially available $0.05 \%$ of water. ${ }^{f}$ PP13 TFSI dried under vacuum and molecular sieves (less than $0.01 \%$ of water).

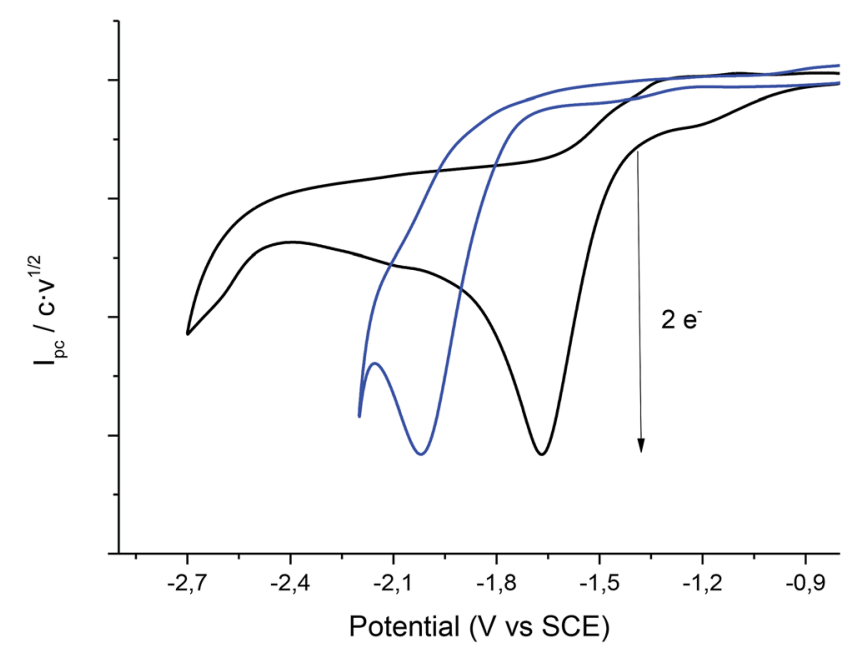

Fig. 4 Cyclic voltammograms (scan rate $0.5 \mathrm{~V} \mathrm{~s}^{-1}$ ) at $25^{\circ} \mathrm{C}$ on a silver electrode of a solution of 20 mM of 1 in PP13 TFSI (black line), EMIM TFSI (blue line) under nitrogen atmosphere.

$\left(11 \mathrm{kcal} \mathrm{mol}^{-1}\right)$ with respect to the glassy carbon electrode in EMIM TFSI and PP13 TFSI, respectively (Table 3, entries 1 and 2).

Table 3 Cathodic peak potential $\left(E_{\mathrm{pc}}\right.$ in $\left.\mathrm{V}\right), \Delta E_{\mathrm{p}}=\left|E_{\mathrm{pc}}-E_{\mathrm{pc} / 2}\right|$ (in $\mathrm{mV}$ ), scan rate: $0.5 \mathrm{~V} \mathrm{~s}^{-1}$, concentration ca. $50 \mathrm{mM}$, charge transfer coefficient $(\alpha)$ for 1 in several solvents using silver as a working electrode at $25{ }^{\circ} \mathrm{C}$ under nitrogen atmosphere

\begin{tabular}{lllcll}
\hline Entry & Solvent & $E_{\mathrm{pc}}(\mathrm{V})$ & $\Delta E_{\mathrm{p}}(\mathrm{mV})$ & $\alpha$ & Number of electrons \\
\hline 1 & EMIM TFSI & -1.96 & 95 & 0.46 & 2.3 \\
2 & PP13 TFSI & -1.66 & 130 & 0.37 & 1.9
\end{tabular}

Fig. 5 shows the cyclic voltammogram of 1 in PP13 TFSI under $\mathrm{CO}_{2}$ atmosphere. A two electron reduction wave was observed at $c a$. $-1.7 \mathrm{~V}$ vs. SCE, which corresponds to the reduction of $\mathbf{1}$. Moreover, in the cathodic scan a new reduction peak at $-2.00 \mathrm{~V} v s$. SCE is also detected, which is ascribed to the electrochemical reduction of $\mathrm{CO}_{2}$ in the IL. The peak current value of this second reduction peak grows when the concentration of $\mathrm{CO}_{2}$ in the ionic liquid increases.

In order to obtain the products 3 and $\mathbf{4}$, control potential electrolyses at $-1.75 \mathrm{~V} v$ s. SCE under saturated $\mathrm{CO}_{2}$ atmosphere were performed in the above-mentioned electrolytic media with silver foil (a control potential electrolysis at $-2.1 \mathrm{~V} v s$. SCE was

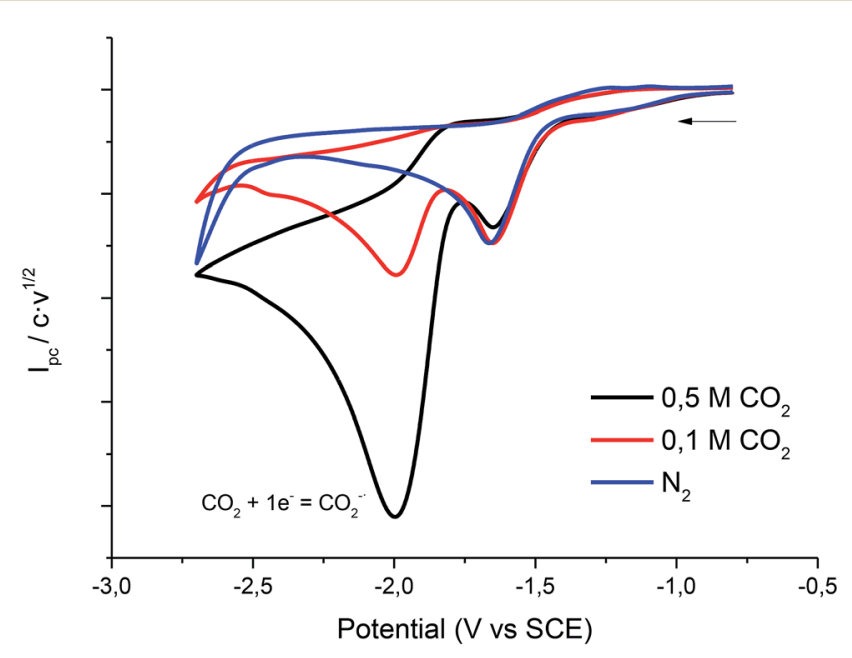

Fig. 5 Cyclic voltammograms (scan rate $0.5 \mathrm{~V} \mathrm{~s}^{-1}$ ) at $25^{\circ} \mathrm{C}$ on a silver electrode of $10 \mathrm{mM}$ of 1 at different concentrations of $\mathrm{CO}_{2}$ in PP13 TFSI. 

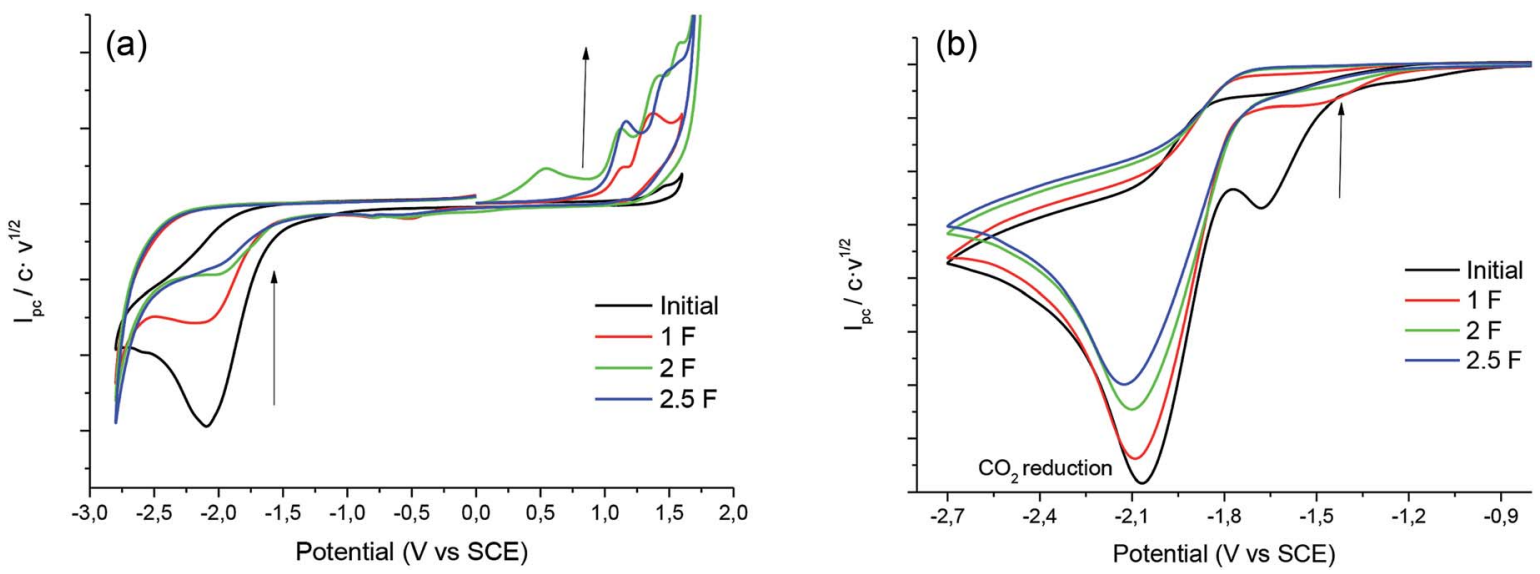

Fig. 6 Cyclic voltammograms (scan rate $0.5 \mathrm{~V} \mathrm{~s}^{-1}$ ) at $25^{\circ} \mathrm{C}$ showing controls of the control potential electrolysis of 1 at $\mathrm{CO}_{2}$ atmosphere in PP13 TFSI on Ag electrode (a) GC electrode (b) Ag electrode.

Table 4 Results of electrocarboxylation of 1 to obtain $\mathrm{R}-\mathrm{COOH} / \mathrm{Me}$

\begin{tabular}{|c|c|c|c|c|c|c|c|}
\hline Entry & Solvent & $E_{\text {applied }}$ & $\mathrm{C} \mathrm{mol}{ }^{-1}$ & Yield $^{a}(\%)$ & Conversion rate $^{b}(\%)$ & Reagent recovery (\%) & $\begin{array}{l}\text { R-H } \\
(\%)\end{array}$ \\
\hline 2 & PP13 TFSI $^{c}$ & -1.75 & 2.0 & 9 & 38 & 76 & 15 \\
\hline 3 & PP13 TFSI $^{d}$ & -1.75 & 2.5 & 82 & 85 & 3 & 15 \\
\hline Entry & Solvent & $E_{\text {applied }}$ & $\mathrm{C} \mathrm{mol}^{-1}$ & Yield (\%) & Conversion rate & Reagent recovery (\%) & $(\%)$ \\
\hline 4 & EMIM TFSI & -2.10 & 2.3 & 18 & 35 & 49 & 33 \\
\hline 5 & $\mathrm{PP} 13 \mathrm{TFSI}^{c}$ & -1.75 & 2.0 & 8 & 35 & 77 & 15 \\
\hline 6 & $\mathrm{PP} 13 \mathrm{TFSI}^{d}$ & -1.75 & 2.5 & 83 & 83 & 0 & 17 \\
\hline
\end{tabular}

${ }^{a}$ Percent yield over isolated product. ${ }^{b}$ Percent of Ibuprofen over consumed reactant. ${ }^{c}$ PP13 TFSI commercially available (0.05\% of water). ${ }^{d}$ PP13 TFSI dried under vacuum and molecular sieves (less than $0.01 \%$ of water).

performed in EMIM TFSI). The reduction processes were easily monitored by means of cyclic voltammetry with a silver electrode and a glassy carbon electrode (Fig. 6), showing the disappearance of $\mathbf{1}$. In all the cases Ibuprofen and its methylated analogue (when iodomethane was added as electrophile) were obtained with moderate to good yields (Table 4). As previously mentioned, it should be noted that, for obtaining yields close to $100 \%$ the IL should be previously dried. The use of commercial IL $(\leq 0.05 \%$ water content) also yields a $20 \%$ of protonated compound 2 .

Finally, the use of silver as a working electrode also allows the electrocarboxylation synthesis of Ibuprofen to be performed in EMIM TFSI. Furthermore, the electrochemical potential required is lower than in carbon electrodes and within the electrochemical window of the IL. However, when electrochemical synthesis is performed in EMIM TFSI, only $30 \%$ of 2 is obtained due to the acidity of the $\mathrm{C} 2-\mathrm{H}$ of the imidazolium moiety.

\section{Conclusions}

In conclusion, a description is presented of an efficient approach for producing high value compounds using $\mathrm{CO}_{2}$ as building block. The methodology employed is based on electrochemical techniques and ILs, which allow eco-friendly chemistry solutions to be used and maintain the aim of offering a potential long-term strategy for using $\mathrm{CO}_{2}$ feedstocks. The use of dried PP13 TFSI as electrolyte helps to overcome the main drawbacks associated with previous processes reported in the literature, where organic solvents, redox mediators, and large quantities of supporting electrolytes are employed. It is important to highlight the economic feasibility and viability of replacing organic aprotic solvents that contain $0.1 \mathrm{M} \mathrm{TBABF}_{4}$ of supporting electrolyte by ILs. Although the price of a single experiment in IL is double that of DMF $+0.1 \mathrm{M}$ of $\mathrm{TBABF}_{4}$, the fact that the IL can be recovered and reused in almost $80 \%$ at the end of the experiment makes this methodology highly viable and attractive. Moreover, changing the nature of the working 
electrode, the synthesis, in terms of potential applied, is improved and allows the use of ionic liquids with a narrow electrochemical window, such as imidazolium ionic liquids. Controlled potential electrolysis of 1-chloro-(4-isobutylphenyl) ethane under $\mathrm{CO}_{2}$ atmosphere allows Ibuprofen to be obtained in good yields and excellent conversion rates. This methodology offers a new "green" route for the synthesis of different carboxylic acids that can be potential non-steroidal antiinflammatory drugs (NSAIDs) in a more environmentally friendly way.

\section{Conflicts of interest}

There are no conflicts to declare.

\section{Acknowledgements}

This work was supported by project CTQ2015-65439-R from the MINECO/FEDER. S. M. acknowledges the Autonomous University of Barcelona for her predoctoral research grant (PIF fellowship).

\section{References}

1 G. Yadav and R. Sen, J. CO2 Util., 2017, 17, 188-206.

2 P. Brunel, J. Monot, C. E. Kefalidis, L. Maron, B. Martin-Vaca and D. Bourissou, ACS Catal., 2017, 7, 2652-2660.

3 P. Nejat, F. Jomehzadeh, M. M. Taheri, M. Gohari and M. Z. Muhd, Renewable Sustainable Energy Rev., 2015, 43, 843-862.

4 R. M. Cuéllar-Franca and A. Azapagic, J. CO2 Util., 2015, 9, 82-102.

5 C. Song, Catal. Today, 2006, 115, 2-32.

6 Y. Xu, L. Isom and M. A. Hanna, Bioresour. Technol., 2010, 101, 3311-3319.

7 Q. Liu, L. Wu, R. Jackstell and M. Beller, Nat. Commun., 2015, 6, 1-15.

8 C. H. Huang and C. S. Tan, Aerosol Air Qual. Res., 2014, 14, 480-499.

9 T. Sakakura, J. C. Choi and H. Yasuda, Chem. Rev., 2007, 107, 2365-2387.

10 N. Yang, S. R. Waldvogel and X. Jiang, ACS Appl. Mater. Interfaces, 2016, 8, 28357-28371.

11 A. Gennaro, C. M. Sánchez-Sánchez, A. A. Isse and V. Montiel, Electrochem. Commun., 2004, 6, 627-631.

12 H. Tateno, K. Nakabayashi, T. Kashiwagi, H. Senboku and M. Atobe, Electrochim. Acta, 2015, 161, 212-218.

$13 \mathrm{~J}$. Albo, M. Alvarez-Guerra, P. Castaño and A. Irabien, Green Chem., 2015, 17, 2304-2324.

14 B. A. Frontana-Uribe, R. D. Little, J. G. Ibanez, A. Palma and R. Vasquez-Medrano, Green Chem., 2010, 12, 2099.

15 A. Gennaro, A. A. Isse, M.-G. Severin, E. Vianello, I. Bhugun and J.-M. Savéant, J. Chem. Soc., Faraday Trans., 1996, 92, 3963-3968.

16 A. A. Isse, M. G. Ferlin and A. Gennaro, J. Electroanal. Chem., 2005, 581, 38-45.
17 A. S. R. Machado, A. V. M. Nunes and M. N. da Ponte, J. Supercrit. Fluids, 2018, 134, 150-156.

18 M. A. Scibioh and B. Viswanathan, Proc. Indian Natl. Sci. Acad., 2004, 70, 407-462.

19 I. Reche, I. Gallardo and G. Guirado, $R S C A d v ., 2014,4$, 65176-65183.

20 R. Matthessen, J. Fransaer, K. Binnemans and D. E. De Vos, Beilstein J. Org. Chem., 2014, 10, 2484-2500.

21 A. A. Isse, S. Gottardello, C. Durante and A. Gennaro, Phys. Chem. Chem. Phys., 2008, 10, 2409-2416.

22 E. E. L. Tanner, C. Batchelor-McAuley and R. G. Compton, J. Phys. Chem. C, 2016, 120, 26442-26447.

23 A. A. Isse, A. Galia, C. Belfiore, G. Silvestri and A. Gennaro, J. Electroanal. Chem., 2002, 526, 41-52.

24 A. A. Isse, A. De Giusti, A. Gennaro, L. Falciola and P. R. Mussini, Electrochim. Acta, 2006, 51, 4956-4964.

25 O. Scialdone, A. Galia, G. Filardo, A. A. Isse and A. Gennaro, Electrochim. Acta, 2008, 54, 634-642.

26 O. Lugaresi, A. Minguzzi, C. Locatelli, A. Vertova, S. Rondinini and C. Amatore, Electrocatalysis, 2013, 4, 353357.

27 P. Khalili, K. Y. Tshai and I. Kong, Composites, Part A, 2017, 100, 194-205.

28 D. Niu, J. Zhang, K. Zhang, T. Xue and J. Lu, Chin. J. Chem., 2009, 27, 1041-1044.

29 A. A. Isse and A. Gennaro, Chem. Commun., 2002, 2798-2799.

30 J. Damodar, S. Krishna Mohan, S. K. Khaja Lateef and S. Jayarama Reddy, Synth. Commun., 2005, 35, 1143-1150.

$31 \mathrm{~J}$. F. Fauvarque, A. Jutand and M. Francois, J. Appl. Electrochem., 1988, 18, 109-115.

32 J. F. Fauvarque, A. Jutand, M. Francois and M. A. Petit, J. Appl. Electrochem., 1988, 18, 116-119.

33 R. Liu, P. Zhang, S. Zhang, T. Yan, J. Xin and X. Zhang, Rev. Chem. Eng., 2016, 32, 587-609.

34 I. Reche, I. Gallardo and G. Guirado, Phys. Chem. Chem. Phys., 2015, 17, 2339-2343.

35 H. K. Lim and H. Kim, Molecules, 2017, 22, 536.

36 D. T. Whipple and P. J. A. Kenis, J. Phys. Chem. Lett., 2010, 1, 3451-3458.

37 J. Li, D. Jia, Z. Guo, Y. Liu, Y. Lyu, Y. Zhou and J. Wang, Green Chem., 2017, 19, 2675-2686.

38 M. Alvarez-Guerra, J. Albo, E. Alvarez-Guerra and A. Irabien, Energy Environ. Sci., 2015, 8, 2574-2599.

39 S. Mena, I. Gallardo and G. Guirado, Catalysts, 2019, 9, 413. 40 L. Sun, G. K. Ramesha, P. V. Kamat and J. F. Brennecke, Langmuir, 2014, 30, 6302-6308.

41 B. A. Rosen, A. Salehi-Khojin, M. R. Thorson, W. Zhu, D. T. Whipple, P. J. A. Kenis and R. I. Masel, Science, 2011, 334, 643-644.

42 R. A. Kjonaas, P. E. Williams, D. A. Counce and L. R. Crawley, J. Chem. Educ., 2011, 88, 825-828.

43 H. Cruz, I. Gallardo and G. Guirado, Electrochim. Acta, 2008, 53, 5968-5976.

44 H. Cruz, I. Gallardo and G. Guirado, Green Chem., 2011, 13, 2531-2542.

45 I. Reche, I. Gallardo and G. Guirado, New J. Chem., 2014, 38, 5030-5036. 
46 I. Reche, I. Gallardo and G. Guirado, ChemElectroChem, 2014, 1, 2104-2109.

47 D. Kodama, K. Sato, M. Watanabe, T. Sugawara, T. Makino and M. Kanakubo, J. Chem. Eng. Data, 2018, 63, 1036-1043.

48 L. R. Faulkner and A. J. Bard, Electrochemical Methods: Fundamentals and Applications, University of Texas at Austin, 2nd edn, 2000, vol. 30.

49 I. Gallardo, G. Guirado and J. Marquet, J. Electroanal. Chem., 2000, 488, 64-72.
50 E. W. Oliver, D. H. Evans and J. V. Caspar, J. Electroanal. Chem., 1996, 403, 153-158.

51 E. W. Oliver and D. H. Evans, J. Electroanal. Chem., 1997, 432, 145-151.

52 L. Xiao and K. E. Johnson, J. Electrochem. Soc., 2003, 150, 307-311.

53 B. Gorodetsky, T. Ramnial, N. R. Branda and J. A. C. Clyburne, Chem. Commun., 2004, 1972-1973.

54 G. H. Lane, Electrochim. Acta, 2012, 83, 513-528. 